\title{
DESENVOLVIMENTO DE UM REATOR TECIDUAL MUSCULAR DE CELULOSE BACTERIANA
}

\author{
G. COLLA $^{1}$ e L. M. PORTO ${ }^{1}$ \\ ${ }^{1}$ Universidade Federal de Santa Catarina, \\ Departamento de Engenharia Química e Engenharia de Alimentos \\ E-mail para contato: \{guilherme_colla; luismar\}@intelab.ufsc.br
}

\begin{abstract}
RESUMO - Vasos sanguíneos artificiais de celulose bacteriana (CB) foram sintetizados utilizando a bactéria Gluconacetobacter hansenii. Os vasos obtidos exibiram propriedades morfológicas e mecânicas similares aos vasos nativos, sua anatomia mostrou membranas concêntricas densas e porosas, mimetizando as camadas íntima e média das artérias humanas. In vitro, a cultura de células de músculo liso de aorta humana (HASMCs) demonstrou capacidade para suportar a colonização celular, permanecendo viáveis após 14 dias de cultura. Os vasos colonizados foram colocados num sistema de fluxo pulsante e mostrou a formação de uma monocamada confluente orientada paralelamente a direção do fluxo. No lúmen, as células em condição dinâmica mostraram maior proliferação e viabilidade em relação ao controle estático. O reator tecidual muscular provou ser uma plataforma promissora para o desenvolvimento de vaso sanguíneo, permitindo ensaios de células e drogas à monocamada de células confluentes que responde à estimulação dinâmica.
\end{abstract}

\section{INTRODUÇÃO}

Segundo a Organização Mundial da Saúde (OMS), a cada ano morrem 17,3 milhões de pessoas em todo o mundo vítimas de doenças cardiovasculares. A estimativa é que em $2030 \mathrm{o}$ total de mortes possa chegar a 23,6 milhões (Mendis et al., 2011). A aterosclerose, doença crônica multifatorial das artérias, que se inicia e se desenvolve a partir de uma idade jovem até que se manifeste clinicamente mais tarde na vida adulta, é a principal causa de obstrução coronariana, aneurisma aórtico, acidente vascular cerebral e gangrena das extremidades. A substituição ou reparo dos vasos sanguíneos danificados podem ser realizados com enxertos vasculares autólogos (do próprio paciente), alogênicos (de um doador), xenogênicos (de outra espécie) ou sintéticos, tornando esse procedimento um tratamento de rotina para muitos tipos de doenças cardiovasculares.

Os enxertos vasculares ideais devem ser biocompatíveis, não trombogênicos, complacentes, resistentes a infecções, e que tenham um longo tempo de manutenção do conduto livre. Os enxertos autólogos, em especial para as artérias, são atualmente preferidos devido à sua superfície não trombogênica, e também à sua força e elasticidade naturais, enquanto as veias 


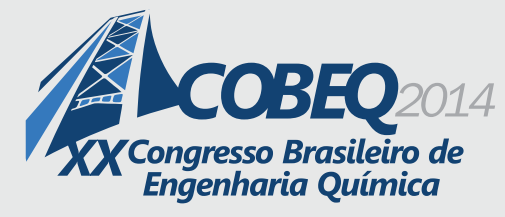

19 a 22 de outubro de 2014

Florianópolis/SC

autólogas são rotineiramente utilizadas como "bypass" nas artérias do sistema circulatório. O uso de vasos naturais, tais como as veias safenas ou artérias mamárias, tornou-se limitado devido às restrições de propriedades mecânicas, no procedimento de anastomoses, com altas taxas de trombogenicidade e restrições de dimensões. Cerca de $10 \%$ a $40 \%$ dos doentes que necessitam de enxertos autógenos de veia safena não apresentam uma veia safena adequada devido à incompatibilidade de tamanho ou doença vascular (Conklin et al., 2002).

Existe atualmente uma grande motivação nos grupos de engenharia de tecidos vascular para o desenvolvimento de vasos sintéticos de pequeno calibre com baixa taxa de trombogenicidade. As principais vantagens de tais enxertos vão da possibilidade de disponibilização de vasos em diversos diâmetros e comprimentos, ao fácil armazenamento, preparação e manuseio dos mesmos. No entanto, sua trombogenicidade inerente e tendência à incompatibilidade permanecem sendo suas principais desvantagens, não se tendo em geral perspectivas realistas de curto prazo. De acordo com essa abordagem, uma das considerações mais importantes é a seleção de um biomaterial adequado para a construção da matriz, com características químicas, mecânicas e de biodegradação adequadas para as diversas possíveis aplicações.

\section{MATERIAIS E MÉTODOS}

\subsection{Material biológico e condições de cultura}

Gluconacetobacter hansenii ATCC 23769 foi rotineiramente mantida em meio de cultura à base de manitol, composto por $25 \mathrm{~g}$ de manitol, $5 \mathrm{~g}$ de extrato de levedura e $3 \mathrm{~g}$ de peptona diluídos em $1 \mathrm{~L}$ de água destilada, $\mathrm{pH}$ ajustado para 6,5 e o meio foi autoclavado por 20 min a $121^{\circ} \mathrm{C}$.

Uma linhagem primária de célula muscular lisa de aorta humana (HASMC) foi rotineiramente mantida em meio 231 suplementado com fator de crescimento de músculo liso (SMGS) e $1 \%$ de penicilina/estreptomicina. As HASMCs foram repicadas quando atingida confluência de aproximadamente $80 \%$ de preenchimento das placas de cultura de tecidos (PCT). A contagem das células foi realizada em câmara de Neubauer, para posteriormente serem redistribuído em novas PCT conforme o planejamento dos experimentos ou para os testes. $\mathrm{O}$ meio de cultura foi trocado a cada 48 horas de cultivo.

\subsection{Produção dos vasos de celulose bacteriana}

Para obtenção dos vasos de celulose bacteriana, construiu-se um aparato constituído de um Erlenmeyer, uma mangueira de silicone de $4 \mathrm{~mm}$ de diâmetro externo e uma bomba de circulação de ar. O sistema Erlenmeyer/mangueiras de silicone foi autoclavado, depois preenchido com meio de cultura inoculado com $G$. hansenii em uma razão de $20 \% \mathrm{v} / \mathrm{v}$ e a mangueira foi ligada à bomba de circulação. $\mathrm{O}$ crescimento microbiano ocorreu em condição estática, à temperatura ambiente $\left(25^{\circ} \mathrm{C}\right)$, durante um período de 12 dias. Os vasos foram 


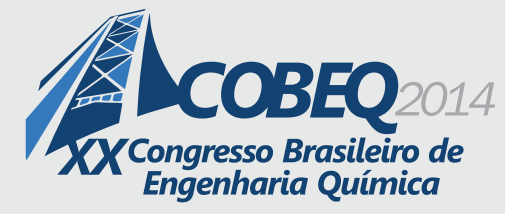

removidas da mangueira de silicone e transferidos para um frasco contendo uma solução de $\mathrm{NaOH} 0,1 \mathrm{M}$, onde foram mantidos por $24 \mathrm{~h}$ a $50{ }^{\circ} \mathrm{C}$ para remoção de bactérias e/ou resíduos do meio. As membranas foram em seguida submetidas a três lavagens sucessivas com água destilada e o pH ajustado a 7,0. Em seguida as membranas foram autoclavadas por $20 \mathrm{~min}$ a $121{ }^{\circ} \mathrm{C}$.

\subsection{Caracterização dos vasos de celulose bacteriana}

A microestrutura das membranas de celulose bacteriana foi caracterizada por microscopia eletrônica de varredura (MEV). As amostras foram previamente congeladas $\left(-80^{\circ} \mathrm{C}\right.$ por $\left.24 \mathrm{~h}\right) \mathrm{e}$ logo depois liofilizadas por $48 \mathrm{~h}$ e visualizadas por MEV.

As propriedades mecânicas dos vasos de celulose bacteriana foram determinadas em um texturômetro Stable Micro Systems, com uma célula de carga de 500 N. Os módulos de tensão de ruptura, alongamento à ruptura e módulo de elasticidade foram determinados através das curvas de tensão-deformação. Foram realizadas cinco repetições de cada amostra, de dimensões: $50 \mathrm{~mm}$ de comprimento e raio $4 \mathrm{~mm}$. A espessura dos biofilmes ficou em 1,1 $\pm 0,2 \mathrm{~mm}$, considerando-se a média de cinco medidas repetidas aleatoriamente. A separação inicial entre as garras e a velocidade do teste foi de $40 \mathrm{~mm}$ e $0,5 \mathrm{~mm} \cdot \mathrm{s}^{-1}$, respectivamente.

\subsection{Semeadura das células musculares lisas nos vasos de celulose}

Os vasos de celulose bacteriana foram previamente esterilizados e distribuídos, à base de um vaso por poço, em uma placa de cultura de seis poços; os vasos foram submersos em meio de cultura 231 (sem SMGS) e permaneceram em estufa incubadora $\left(37{ }^{\circ} \mathrm{C}\right.$ e $5 \%$ de $\left.\mathrm{CO}_{2}\right)$ por 24 horas. Após 24 horas o meio de cultura foi removido e foram semeadas $1,2 \times 10^{5}$ células $\mathrm{cm}^{-2} \mathrm{de}$ vaso, no interior do vaso. Células de passagem 5 foram cultivadas em meio 231 suplementado, conforme descrito anteriormente. As células foram mantidas em condições de cultivo por 14 dias, e o meio foi renovado a cada dois dias de cultivo.

\subsection{Caracterização de adesão celular por MEV}

Para caracterização da adesão das células nos vasos de $\mathrm{CB}$, as amostras foram secas pela técnica de ponto crítico de $\mathrm{CO}_{2}$ e posteriormente distribuídas sobre fitas de carbono que estavam aderidas sobre os stubs, então recobertas com uma camada de ouro. Após recobrimento as amostras foram analisadas por MEV.

\subsection{Viabilidade e proliferação celular}

A viabilidade e a proliferação celular foram determinadas pela atividade mitocondrial das células, através da utilização do ensaio colorimétrico de MTS [3-(4,5-dimetiltiazol-2-il)-5-(3carboximetoxifenil)-2-(4-sulfofenil)-2H-tetrazólio]. HASMCs foram semeadas no interior dos vasos de CB na densidade de $1,2 \times 10^{5}$ células $\cdot \mathrm{cm}^{-2}$ (BACKDAHL et al., 2006). A viabilidade $\mathrm{e}$ proliferação celular foram avaliadas em função do tempo de cultura, $0,1,2,3,7$ e 14 dias. $\mathrm{O}$ 


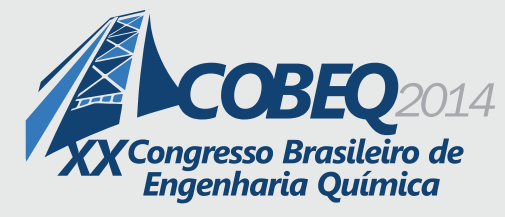

ensaio do MTS quantifica, através da medida de concentração, um produto solúvel resultante de uma reação do MTS com mitocôndrias das células viáveis; a medida é feita por espectrofotometria UV-VIS (absorbância a $490 \mathrm{~nm}$ ) e é diretamente proporcional ao número de células vivas em cultura.

\subsection{Desenvolvimento do reator biológico tecidual muscular}

Os vasos de CB foram previamente semeados com células HASMC na densidade de $1,2 \times 10^{5}$ células $\mathrm{cm}^{-2}$ em condições estáticas, em uma placa de Petri durante sete dias. Após o sétimo dia um dos vasos foi acoplado ao sistema de fluxo pulsante, que consistiu de um sistema de perfusão de loop fechado. O sistema consiste em três partes: uma câmara de cultura cilíndrica de borosilicato, uma bomba peristáltica e tubulações; um outro vaso permaneceu em condição estática. Iniciou-se o escoamento do meio de cultura pelo interior do vaso, começando com uma frequência de pulso de $0,5 \mathrm{~Hz}$, com aumento gradual até $1,0 \mathrm{~Hz}$, onde o vaso permaneceu até o final do experimento. $\mathrm{O}$ número de Reynolds médio para a vazão máxima $30 \mathrm{~mL} \cdot \mathrm{min}^{-1}$ foi de 347, indicativo de escoamento laminar. Os vasos de CB foram analisados após sete dias em condições dinâmicas e estáticas através de testes de adesão celular por $\mathrm{MEV}$, e viabilidade e proliferação celular, como já descrito anteriormente.

\section{RESULTADOS E DISCUSSÃO}

Membranas de celulose bacteriana são produzidas quando a bactéria Gluconacetobacter hansenii é cultivada em meio de cultura à base de manitol em condições estáticas de cultura, formando assim uma membrana de celulose na interface líquido/ar. Esta membrana é formada por um grande número de camadas de celulose finas e cresce em espessura para dentro do meio líquido (Borzani e Souza, 1995). Assim, o aparato desenvolvido neste trabalho possibilita a produção de vasos de CB em torno de uma mangueira de silicone submersa em meio de cultura, por onde o ar é capaz de se difundir pelos poros da mangueira de silicone, e a porosidade impede a migração de bactérias (Bodin et al., 2007). Trabalhos anteriores mostraram que membranas de celulose podem formar-se sem a circulação de ar (Oliveira et al., 2013), contudo Bodin e colaboradores demonstraram que a resistência mecânica desse tipo de membrana é afetada pela quantidade de oxigênio difundida. Os vasos de CB produzidos neste trabalho apresentaram as dimensões de $10 \mathrm{~cm}$ de comprimento, $4 \mathrm{~mm}$ de diâmetro e 1,0 $\pm 0,2 \mathrm{~mm}$ de espessura (Figura 1a).

As amostras liofilizadas foram caracterizadas quanto à sua microestrutura por MEV. A microestrutura da membrana de CB obtida através do corte transversal da amostra (Figura 1b) mostra uma superfície do interior do vaso com alta densidade de nanofibras de celulose que se organizam umas próximas as outras de forma entrelaçada (alta densidade) enquanto a superfície oposta, exterior do vaso, é caracterizada por uma rede de nanofibras de CB que se organizam de forma espaçada (baixa densidade), corroborando relatos da literatura (Bäckdahl et al., 2006; Stumpf et al., 2013). A Figura 1(c) mostra detalhes da superfície com alta densidade de nanofibras de $\mathrm{CB}$, referentes à superfície mantida em contato com o ar durante o crescimento 


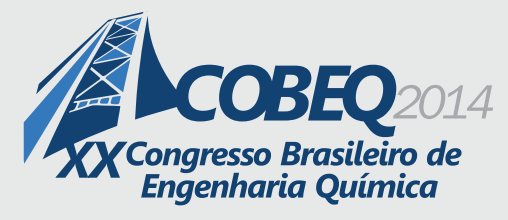

19 a 22 de outubro de 2014

Florianópolis/SC

bacteriano. Já a Figura 1(d) mostra detalhes da superfície porosa da malha de celulose, voltada para a interface submersa no meio de cultivo.
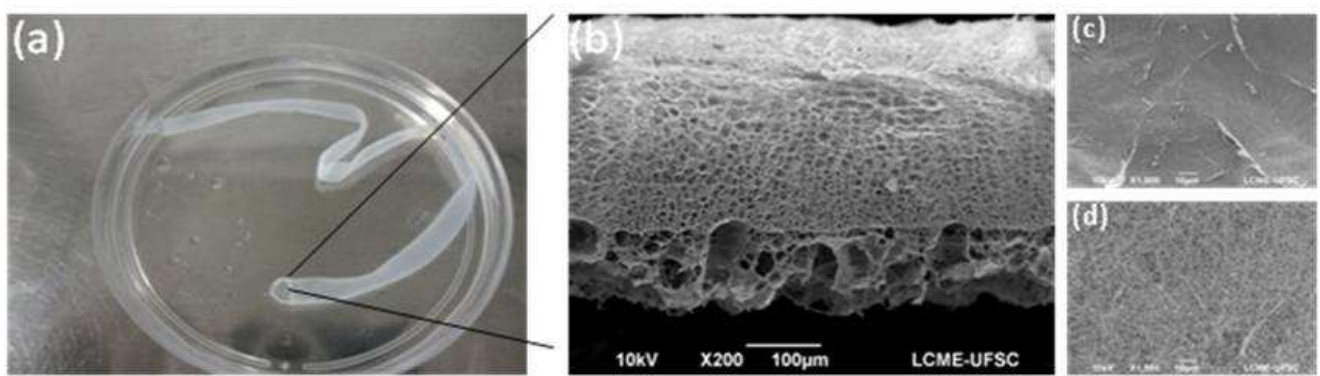

Figura 1 - (a) Vaso de celulose bacteriana produzido durante doze dias de cultivo estático após purificação. Visualização da membrana de celulose bactéria por MEV; (b) Vista lateral da membrana de celulose bacteriana; (c) e (d) mostram detalhes da região densa e porosa, respectivamente.

Ensaios mecânicos nos vasos de CB no estado hidratado (hidrogel de celulose) e previamente tratadas com $\mathrm{NaOH} 0,1 \mathrm{M}$ foram realizados para verificar a tensão de ruptura, o módulo de elasticidade e o alongamento relativo sob tensão antes da ruptura. A Figura 2 mostra uma curva típica de tensão-deformação para os vasos de celulose bacteriana hidratados, quando expostos a uma tensão progressiva.

Os vasos de CB exibiram alto alongamento relativo sob tensão, antes de romper, tendo a ruptura ocorrido a uma deformação de $24,5 \pm 2,8 \%$. A resistência à ruptura foi de $0,18 \pm 0,026$ Mpa; essa tensão de ruptura é similar às relatadas em outros trabalhos descritos na literatura para celulose bacteriana produzida no formato tubular e hidratada, onde foram encontrados resultados próximos a 0,4 MPa (Bodin et al., 2007) ou 0,59 MPa (Putra et al., 2008) com alongamentos de $30 \%$ e $28 \%$, respectivamente. O módulo de elasticidade de Young, de 0,01 $\pm 0,003 \mathrm{MPa}$, também está de acordo com resultados de vasos obtidos de celulose bacteriana, relatados na literatura como 0,02 MPa (Putra et al., 2008) e 0,59 $\pm 1,2 \mathrm{MPa}$ (Bäckdahl et al., 2006). Quando se compara os valores de ruptura de vasos nativos 0,224 $\pm 0,041 \mathrm{MPa}$ com os de vasos de CB produzido neste trabalho, têm-se valores compatíveis.

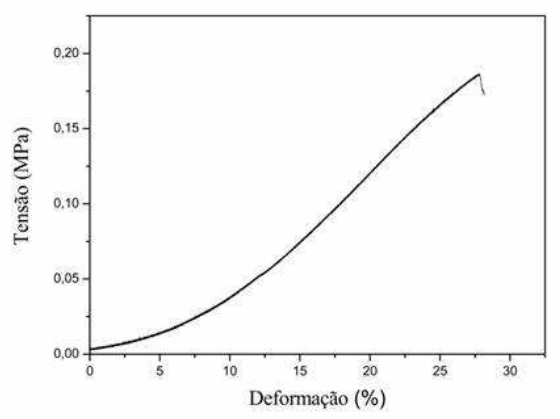

Figura 1 - Curva típica de tensão-deformação de vasos de celulose bacteriana hidratados. 


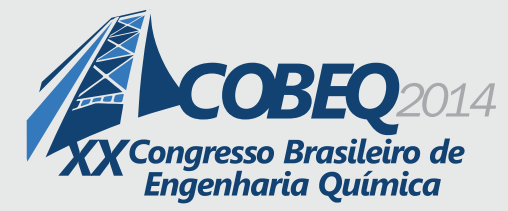

O ensaio colorimétrico do MTS foi utilizado para avaliação quantitativa da viabilidade celular de HASMCs em função do tempo de cultura estática. Neste ensaio, a atividade mitocondrial foi avaliada no tempo inicial $(\mathrm{t}=0)$ e após $1,2,3,7$ e 14 dias de cultura, Figura 3(a). No primeiro dia de cultura, apenas $73 \%$ das células semeadas aderiram ao vaso de CB; no entanto, no $2^{\circ}$ dia uma fase de proliferação celular pode ser observada, atingindo no $3^{\circ}$ dia aproximadamente a mesma quantidade de células semeadas, e permanecendo praticamente constante até o $7^{\circ}$ dia. Por fim, até o $14^{\circ}$ dia houve uma lenta proliferação celular, atingindo uma proliferação $37 \%$ maior do que as células aderidas no primeiro dia. Com o objetivo de investigar a adesão celular nos vasos de celulose bacteriana, HASMCs foram semeadas no lúmen do vaso produzido, sobre a superfície densa. Como pode ser observado nas imagens de MEV, Figura 3(b), as HASMCs após um dia de cultivo apresentaram morfologia arredondada, típico de células pouco ou recém aderidas; já em 2 e 3 dias de cultivo, observa-se que as células proliferaram e alteraram o perfil de adesão para uma morfologia espraiada, indicando uma melhor adesão celular sobre a celulose. Nos tempos de 7 e 14 dias de cultivo, têm-se células alongadas; em especial, no $14^{\circ}$ dia observa-se a presença de projeções de citoesqueleto, indicando boa aderência e adaptação sobre a celulose.

(a) Viabilidade

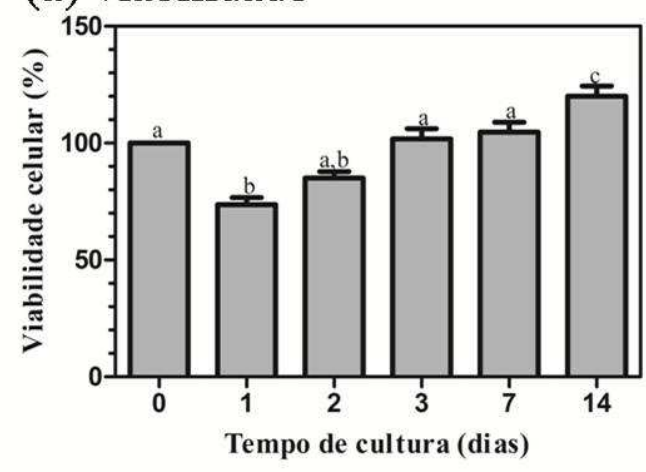

(b)Adesão

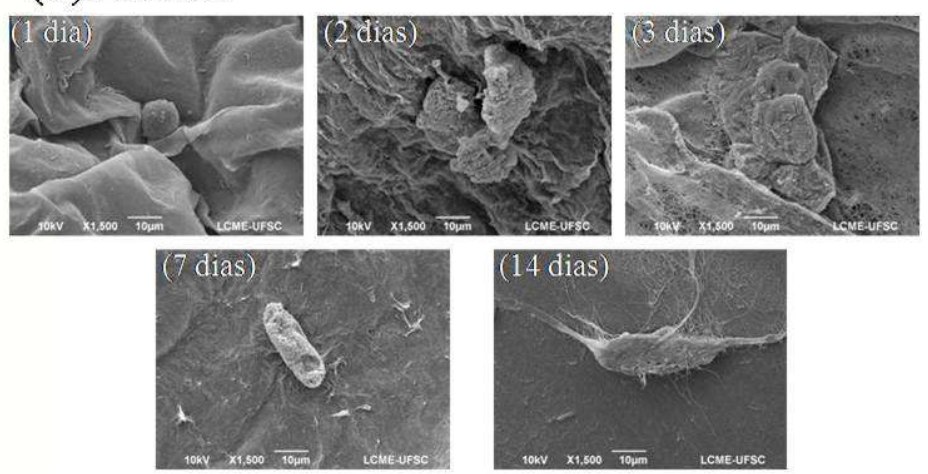

Figura 3 - (a) Análise quantitativa de MTS da HASMCs cultivadas nos vasos de celulose bacteriana em função do tempo de cultura; (b) Adesão e morfologia das HASMCs cultivadas no interior dos vasos de celulose bacteriana, e analisadas em diferentes dias de cultura celular: 1, 2, 3,7 e 14 dias.

As HASMCs semeadas e cultivadas nos vasos de CB sob condições estática e pulsante de escoamento no sistema de fluxo pulsante foram avaliadas para o desenvolvimento de uma camada semelhante à túnica média vascular encontrada nos vasos nativos. Macroscopicamente, os vasos exibiram uma boa integridade, sem deformação durante os 14 dias de cultura no sistema de fluxo pulsante (Figura 4a).

Os resultados de viabilidade e proliferação celular determinados quantitativamente por ensaio com MTS demonstram um crescimento celular nos vasos de CB tanto em cultura estática quanto em cultura dinâmica. O número de células nos vasos de $\mathrm{CB}$ sob fluxo pulsante durante 14 dias foram significativamente maiores do que na cultura estática (Figura 4b), o que corrobora os 


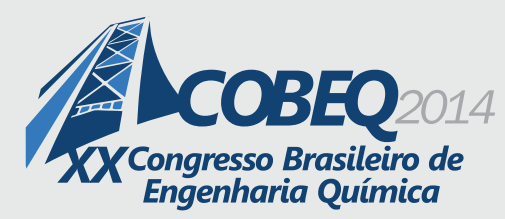

19 a 22 de outubro de 2014

Florianópolis/SC

resultados de Zhang e colaboradores, que demonstraram um crescimento superior de células musculares sob condição dinâmica quando comparado com condições estáticas (Zhang et al., 2009).

(a)

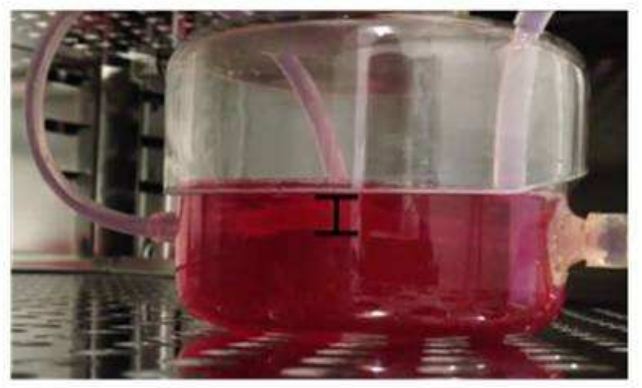

(b)

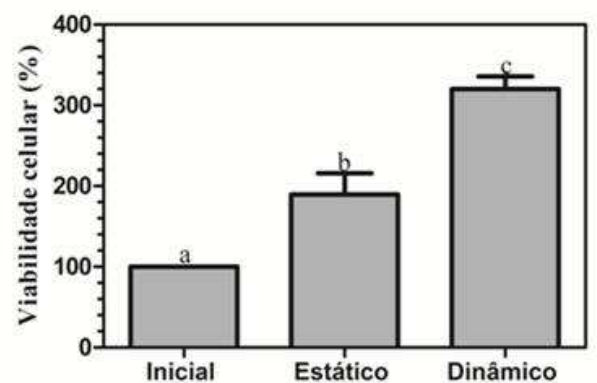

(c)

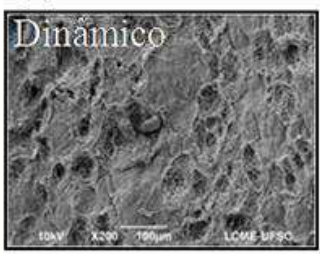

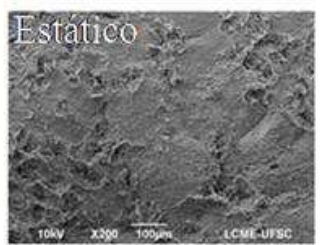

Figura 4 - Sistema de fluxo pulsante para cultura do vaso de celulose bacteriana celularizado com HASMCs (a) Imagem do reator com o vaso no seu tamanho original; (b) Análise quantitativa da viabilidade celular por MTS; (c) Imagem de MEV das HASMCs semeadas sobre a superfície luminal dos vasos de celulose bacteriana em condição estática e dinâmica de fluxo pulsante.

O alongamento celular nos vasos sob condição pulsante e direcionada na direção do fluxo mimético em comparação com a cultura estática (Figura 4c) é considerado como uma característica contrátil, essencial para células musculares em vasculatura do sistema circulatório (Zhang et al., 2009). Assim, o vaso de celulose bacteriana em condições dinâmicas constitui uma plataforma adequada para o cultivo de células musculares humanas, conferindo às mesmas um fenótipo típico de células musculares em vasos sanguíneos nativos, conforme as observações até aqui realizadas.

\section{CONCLUSÕES}

Vasos de celulose bacteriana foram produzidos com $4 \mathrm{~mm}$ de diâmetro, com duas superfícies distintas, uma densa e outra porosa, semelhante às túnicas encontradas nos vasos nativos, com propriedades mecânicas adequadas quando comparadas com vasos naturais humanos. Os vasos de celulose bacteriana foram celularizados com HASMCs e cultivados durante 14 dias com sucesso, mantendo a viabilidade e proliferação celular durante todo o teste; a avaliação da adesão celular indicou boa aderência celular sobre a celulose bacteriana.

Um reator biológico tecidual muscular foi desenvolvido com os vasos de celulose bacteriana celularizados com células de aorta humana de músculo liso e exposto ao sistema de fluxo pulsante durante sete dias, sob condição dinâmica. As células na condição dinâmica apresentaram um alinhamento ao fluxo, típico de células musculares em ambiente natural, e uma viabilidade celular superior à condição estática. Este equipamento pode ser utilizado para teste de 
integridade dos vasos, estudos de respostas celulares a diferentes estímulos, bem como terapias e dispositivos diagnósticos e de ensaios biomédicos.

\section{REFERÊNCIAS}

BÄCKDAHL, H.; HELENIUS, G.; BODIN, A.; NANNMARK, U.; JOHANSSON, B. R.; RISBERG, B.; GATENHOLM, P. Mechanical properties of bacterial cellulose and interactions with smooth muscle cells. Biomaterials, v. 27, n. 9, p. 2141-2149, 2006.

BODIN, A.; BÄCKDAHL, H.; FINK, H.; GUSTAFSSON, L.; RISBERG, B.; GATENHOLM, P. Influence of cultivation conditions on mechanical and morphological properties of bacterial cellulose tubes. Biotechnol. Bioeng., v. 97, n. 2, p. 425-434, 2007.

BORZANI, W.; SOUZA, S. Mechanism of the film thickness increasing during the bacterial production of cellulose on non-agitaded liquid media. Biotechnol. Lett., v. 17, n. 11, p. 1271$1272,1995$.

CONKLIN, B. S.; RICHTER, E. R.; KREUTZIGER, K. L.; ZHONG, D. S.; CHEN, C. Development and evaluation of a novel decellularized vascular xenograft. Med. Eng. Phys., v. 24, n. 3, p. 173-183, 2002.

MENDIS, S.; PUSKA, P.; NORRVING, B. Global Atlas on Cardiovascular Disease Prevention and Control Geneva: World Health Organization. 2011.

OLIVEIRA, V. A.; RAMBO, C. R.; PORTO, L. M. Production and in vitro degradation of bacterial cellulose tubular structures. Polímeros, v. 23, n. 4, p. 559-564, 2013.

PUTRA, A.; KAKUGO, A.; FURUKAWA, H.; GONG, J. P.; OSADA, Y. Tubular bacterial cellulose gel with oriented fibrils on the curved surface. Polymer, v. 49, n. 7, p. 1885-1891, 2008.

STUMPF, T. R.; PÉRTILE, R. A. N.; RAMBO, C. R.; PORTO, L. M. Enriched glucose and dextrin mannitol-based media modulates fibroblast behavior on bacterial cellulose membranes. Mat. Sci. Eng. C., v. 33, n. 8, p. 4739-4745, 2013.

ZHANG, X.; WANG, X.; KESHAV, V.; WANG, X.; JOHANAS, J. T.; LEISK, G. G.; KAPLAN, D. L. Dynamic culture conditions to generate silk-based tissue-engineered vascular grafts. Biomaterials, v. 30, n. 19, p. 3213-3223, 2009. 